\title{
LA CAZA EN EL SIGLO XVIII: SOCIEDAD DE CLASE, MENTALIDAD REGLAMENTISTA
}

\author{
Ceferino Caro López \\ I.E.S. «Beatriz Galindo» Madrid
}

RESUMEN: A pesar de sus declaraciones de innovación, la política ilustrada en asuntos sociales mantuvo durante todo el siglo XVIII una continuidad sustancial con las actitudes mentales de los siglos anteriores, como puede verse por las leyes de caza y pesca. Éstas tendían, por una parte, a establecer un control riguroso sobre una actividad tradicional, y por otra, a bomogeneizar su práctica en todos los territorios de la Corona y reservarla a las capas privilegiadas de la sociedad. En este sentido lo que pudiera parecer meramente episódico se revela como un paso más del absolutismo para intentar formar una sociedad fuertemente dirigida. La reglamentación de la caza y la pesca además se convertía en producción de ideología en defensa de la sociedad de clase y de la mentalidad aristocrática.

PALABRAS ClAVE: Ilustración. Mentalidad social. Conciencia aristocrática.

ABSTRACT: Despite its innovative claims, the social policy of the Spanish Enlightenment was substantially a sequel to the mental attitudes of the previous centuries, as regulatios regarding hunting and fishing practices reveal. These laws tended, on the one hand, to control firmly a traditional activity, and, on the other hand, aimed at homogenizing this practice in the whole territories of the monarchy and limit its extent to the aristocracy. Thus, a mere episode becomes a further step taken by absolutism in order to shape a strongly directed class society. Besides, bunting and fishing regulations became an ideological output aiming at the defence of class society and aristocratic consciousness.

KEY WORDS: Enlightenment. Social mentality. Aristocratic consciousness. 
Ningún ejercicio corresponde así al de la guerra como el de la caza, a quien es anejo el cansancio, la sed y el hambre, y aun a veces la muerte

(Cervantes, Persiles)

Tú mantienes el cuerpo duro y fuerte /que ni teme a la guerra, ni a la muerte

(N. Fernández Moratín, La Diana)

Dos citas de autores separados por ciento cincuenta años de cultura y sensibilidad, ¿mentalidades de dos siglos aparentemente opuestos pero más cercanas de lo que pareciera? El objeto de este trabajo consiste en presentar un ejemplo más de las contradicciones de la Ilustración en España, y de cómo bajo las afirmaciones de voluntad de superación de las preocupaciones del pasado aún latía una cierta continuidad ideológica en lo que se refiere a los prejuicios sociales. También se podrá notar el desfase entre la teoría de los reformadores y gobernantes en los niveles más altos del Poder y la práctica de las instancias administrativas en los grados inferiores partiendo de un hecho aparentemente secundario como puede ser el de la legislación de la caza porque se notará que muchas veces las trabas a esta práctica se levantaban en los ámbitos locales, podría decirse que mediante reglamentos que interpretaban unas normas promulgadas por la Corona con voluntad de que se aplicaran a todo el reino. Al tomar en consideración ese corpus jurídico para interpretar su significación no ha sido necesario buscar, como se debe hacer en el análisis literario, el metatexto, que «significa suponer que tanto el productor (o el autor) escribe su texto respondiendo a un horizonte de expectativas de su audiencia, como que la audiencia interpreta el texto en cuestión sobre el horizonte de expectativas que el texto orienta por la clase a la cual pertenece» ${ }^{1}$, porque los mismos legisladores expresaban directa y explícitamente sus convicciones sociales y las leyes de caza y pesca revelan descarnadamente la mentalidad clasista y aristocrática que las sostenía. Aquí se pretende ilustrar la relación dialéctica entre las intenciones sociales de gobernantes y gobernados tal y como se manifiestan precisamente en el ámbito de la caza y también de qué modo la legislación se usó en calidad de instrumento de dominio de clase.

En la historia del hombre la caza ha sido un medio de conseguir alimento y mientras no fue más que una actividad práctica no se la consideraba una diversión sino una necesidad primaria; ahora la cuestión es muy distinta si se la observa desde el punto de vista de las clases favorecidas porque una vez que viene a faltar la motivación utilitaria cazar se convierte en entretenimiento, se aleja de lo puramente necesario y se la considera un deporte. Por mucho que en la Edad Moderna se fueran perdiendo gradualmente algunas modalidades tradi-

1 Mignolo, W.D.: «El metatexto», Modern Language Notes 96, 2, 1981, p. 360. 
cionales de la venación, las diferentes disposiciones legales que más abajo se examinarán demuestran que la práctica se fue limitando cada vez más a los grupos privilegiados y a la aristocracia, ya fuera esgrimiendo razones de policía - las armas de fuego eran una amenaza para el orden público- ya exaltando abiertamente los valores aristocráticos de la caza, con lo que su espíritu aristocrático siguió íntegro porque en el siglo XVIII la tendencia del legislador apuntaba a restringir el derecho de cazar y pescar a grupos cada vez más concretos y reducidos.

La legislación de la caza en sentido estricto arranca de unas medidas reguladoras dictadas en sus orígenes sólo para los Reales Sitios, especialmente para el monte de El Pardo, pero en ningún caso es posible hablar de solución de continuidad con la política de la dinastía anterior. Empieza con la Real Cédula de 29 de julio de 1715 que imponía la aplicación de otra disposición de 24 de septiembre de 1705 sobre caza y pesca en los Reales Sitios, porque

De muchos años a esta parte está vedada, y acotada, para nuestra recreación, y entretenimiento, la caza mayor, y menor, y aves de bolatería de nuestro Bosque, y Monte del Pardo,

y después se cuenta la Real Cédula para Aranjuez de 1721; más tarde saldrían las leyes de 1735 , dos de 1747 , el importante texto de 1752 y la medida fechada en 1781, una vez más relativos a El $\mathrm{Pardo}^{2}$. Durante la primera mitad del Setecientos, como se puede ver, la caza se regulaba exclusivamente para prohibirla en los Reales Sitios; solamente en 1752 aparecen las primeras medidas de alcance general, dirigidas a imponer una normativa común a toda la Península, dando así origen a varios e interesantes conflictos de jurisdicción y soberanía, entre los que se pueden destacar como ejemplo los Capítulos de los procuradores de Álava de 22 y 26 de abril de 1753 para retocar la Real Orden de 14 de septiembre de 1752, y a los que bien pronto seguirían la Aprovación de

2 AHN, Reales Cédulas, 5017. «Considerando quasi apurada, y minorada está la caza de dicho nuestro Bosque, y Monte del Pardo, sitio Real de la Zarçuela, Casa de Campo, y su término, por la poca aplicación que se pone en su guarda, y custodia, y en castigar a tantos, como alentados de la tolerancia insultan los referidos sitios». El conjunto de las disposiciones legales está formado por las Reales Cédulas (en adelante, RC) 4/XI/1640, 1/VI/1647, 11/II/1682 y 4/VIII/1684, 21/I/1721, Archivo Histórico Nacional, (en adelante, AHN) Consejos legajo 39467/9; 21/I/1721, AHN Cons leg 39467/9; 21/XII/1735, AHN Cons libro 1516/25; 23/IV/1747 y 9/XII/1747, AHN Cons lib 1516/25 y 31; 14/IX/1752, AHN Cons lib 1480/65; Real Resolución 19/VI/1756, AHN Cons leg 49504; Ynstrucción general [...] en el Reyno de Mallorca... AHN Cons leg 49498; 16/VI/1758 y 14/VII/1758, AHN Cons leg 49498; 1/XI/1766, AHN Cons lib 1511/7; 3/III/1769, AHN Cons leg 39487/5; 16/I/1772 y Real Orden 23/II/1778, AHN Cons leg 49511/I; RO 6/XII/1774, AHN Cons leg 39503/11 y lib 1363, ff. 84 ss. Ordenanzas de las Alcaldías del Pardo 4/VII/1781, Biblioteca Nacional mss. 9/19063. Dejando de parte las medidas específicas de los Reales Sitios —El Pardo, El Escorial, Aranjuez, Valsaín - la legislación se emanaba para que tuviera aplicación en toda la Península. 
diferentes Capítulos aumentados a la Real Provisión de veda de Caza y Pesca para la ciudad de Calahorra de 18/VII/1754 y de Tembleque del mismo año ${ }^{3}$, resueltos siempre a favor de la norma general. Los únicos particularismos admitidos eran los fundados en especificidades de la biodiversidad geográfica pero nunca en usos o derechos tradicionales; antes al contrario algunas leyes anulaban costumbres locales bien arraigadas, como por ejemplo en 1775 cuando la Villa de Lucena suplicaba

Sobre que se declare que las ordenanzas que están establecidas para la dibersión titulada de Palomas Laudivinas en dicha ciudad no se oponen a la Real Orden de beda de caza y pesca y que en su consecuencia se les permita continuar en la dicha dibersión.

Pretendían poder seguir disparando escopetas en las fiestas, pero el Consejo no permitía la «diversión palomítica» porque ocurría en tiempos prohibidos, en mayo y septiembre, como estipulaba la Real Cédula de $1772^{4}$. En su conjunto estas medidas tenían varios puntos en común, el primero de los cuales era evidentemente el de reglamentar la caza en los territorios a los que se referían organizando esa normativa mediante un minuciosísimo articulado.

Cazar era ocupación sólo de nobles o a lo sumo de las capas superiores de la sociedad porque presuponía en quienes la practicaban tiempo libre, capacidad económica y valor físico: exactamente las cualidades que la mentalidad aristocrática negaba tradicionalmente y por principio al plebeyo5. Lo decía Bujanda a finales del Seiscientos: «El afecto a la caza ha sido siempre muy frequente en los Reyes, y Señores»:

La causa final tiene mixtura, y concernencia con la motiva, en que he discurrido, pues entrambas miran a la Grandeza y Real Magestad: la primera, para el divertimiento de los cuidados, y entretenimientos urbanos, que no son tan decorosos, ni útiles a tales Príncipes; la segunda, por ser lustre necessario a tanta grandeza la prohibición, en que deben ceder los inferiores su derecho, como en privilegio de su mayor Nobleza. [...] De donde se reconoce que la prohibición y facultad absoluta que su Real Magestad tiene en la caza no es sin fundamento, antes razonable, pues no mira a violencia ni a privación de derecho sin causa, sí a conservar su grandeza y privilegio de su superioridad y nobleza,

pues de haber faltado esa "prohibición» también se resentiría la grandeza del monarca. Bujanda justificaba las limitaciones de la caza a favor del rey porque

\footnotetext{
AHN Cons leg 49546 para Calahorra y Tembleque; Don Benito, 1778, leg 49511/I.

AHN Cons leg 39495/4.

5 Para una discusión teórica sobre los términos patricio y plebeyo y su significado descriptivo/normativo, véase E. T. Thompson, Costumbres en común, Barcelona, Crítica, 1995, cap. 2, pp. 29 ss. El mismo autor también discute el alcance del concepto de paternalismo en las relaciones sociales del
} Antiguo Régimen 
si todos la practicaran se estropearían montes y ríos, con lo que se causaría grave daño al bien común ${ }^{6}$. En el siglo Dieciocho la Ilustración mantenía esa misma mentalidad mientras que su ideología declarada se dirigía aparentemente hacia unos fines de superación de las preocupaciones sociales del pasado. Todo se hace patente tras la lectura del Cazador instruido de Arellano, publicado a finales del reinado de Carlos III:

Sólo trato del modo de cazar con el celebrado instrumento de la escopeta; porque además de ser propio de diestros, y esclarecidos sugetos, no estaba en mí el dar reglas para saber tan abatido, quanto ruin modo de trampas, reclamos y lazos prohibidos por Leyes y Pragmáticas de estos Reynos?

Ruin y abatido son calificativos aplicados al saber y al modo de practicar la caza, pero evidentemente se refieren a los sujetos que tales maneras seguían, esto es a los plebeyos. Así que estudiar las leyes de caza y pesca del siglo XVIII permite una vez más tomar conciencia de la dualidad entre teoría y práctica de la Ilustración española que a veces llegaba a una verdadera y propia esquizofrenia: por una parte los pensadores ilustrados mantenían el esfuerzo de transformar el país en rica huerta y productiva, y por otra inmovilizaban extensísimos territorios para dedicarlos a la práctica venatoria de la Corte realizando una amortización muy parecida a la que combatían cuando se daba a favor de la Iglesia o de los mayorazgos ${ }^{8}$; por una parte sostenía que la verdadera dignidad de los hombres dependía de su utilidad social, por otra limitaba la caza a las capas sociales más elevadas, reconociendo abiertamente que los trabajadores y los pobres no tenían derecho de practicarla y poniendo en tela de juicio los reconocimientos puramente formales que a veces se les otorgaba. Por cierto que el metatexto ideológico de toda la legislación — plasmada a veces por el mismo Campomanes - revela una posición radicalmente distinta a la de ese

6 De Bujanda, G.: Compendio de las leyes expedidas sobre la caza, nuevamente defendida, e ilustrada, práctica civil y criminal en la materia de Reales Bosques, y Sitios, y su expedición en los Tribunales, Madrid, Francisco Sanz, 1691, pp. 3, 5-7.

7 De Arellano, J.M.: El cazador instruido, y arte de cazar con escopeta y perros, a pie y a caballo, [Madrid 1788], Valencia, 1993, p. 3.

8 Sólo bien entrado el siglo XIX, y por meras razones de tesorería, se pensó en cambiar el uso de los cazaderos reales según criterios de rentabilidad económica. Véase el Informe del Veedor de este Real Sitio sobre el mejor aprovechamiento de los terrenos consagrados hasta aquí a la caza, 23 de noviembre de 1808, promovido por la Junta Central Gubernativa del Reyno: «Dando a cada terreno de los hasta aquí consagrados a la diversión de la caza un destino más provechoso», Archivo General de Palacio, Patrimonio, Casa de Campo, legajo 15. Para la visión económica ilustrada, se puede ver el Informe sobre la ley agraria de Jovellanos y también Meléndez Valdés, en su Epístola VII cuando criticaba la aristocracia parasitaria, al igual que lo habían hecho antes Feijoo, Torres Villarroel, Cadalso o Cabarrús. Jovellanos sostenía que se debía preferir una organización económica y productiva racional «como los ingleses» antes que una «como los turcos», Obras, Madrid 1956 pp. 7-10). Véase también CARO LÓPEZ, C.: «Los Reales Sitios de Madrid en el siglo XVIII: extensión y servidumbres», Anales del Instituto de Estudios Madrileños, XLII, 2002. 
autor en sus tratados teóricos9. El estudio de las medidas de reglamentación también pondrá en luz otros dos aspectos típicos del absolutismo ilustrado, es decir la voluntad de controlar y regular la totalidad de la vida social, y, como contrapunto, la facilidad con que el Poder estaba dispuesto a admitir excepciones a las normas que él mismo determinaba.

Conviene en primer lugar recordar algunas facetas de los planteamientos reformistas dieciochescos para comprobar después hasta qué punto se respetaban en las disposiciones legales. La Ilustración, evidentemente, no fue reaccionaria, pero tampoco revolucionaria aunque bajo muchos puntos de vista, en cuanto movimiento político y cultural, se tratara de un fenómeno social que preconizaba con las consabidas limitaciones una cierta libertad individual. Sobre este punto concreto es difícil compartir el juicio que da Maravall del alcance de la política de los ilustrados cuando dice que «Lo que quieren es eliminar el afán por el ennoblecimiento, de parte de las clases burguesas o de la pequeña burguesía - agraria o artesanal (labradores o artesanos y comerciantes) — porque lleva al engaño, y porque ellos en cambio tienen programas de ascensión, más útiles y más valiosos» ${ }^{10}$. De las dos partes de esta afirmación, es innegable la primera, mientras que el alcance de los «programas de ascensión» social ilustrados se ceñía sobre todo a garantizar un nivel de paz social siempre en equilibrio precario. Los afanes sociales ilustrados podían sí indicar una dirección, pero el fondo de su mentalidad apuntaba hacia otras convicciones. El metatexto de las leyes de caza indica también que era pura propaganda la postura borbónica al achacar todas las culpas del retraso español a la mentalidad aristocrática y de desprecio del trabajo productivo típico de la visión social de los Austrias ${ }^{11}$.

De las premisas ilustradas nacía el afán por fomentar la educación popular aunque se limitaba exclusivamente al objeto de preparar buenos súbditos, dignificando socialmente el trabajo pero sólo en la medida en que ello significaba favorecer el aumento de la productividad. Para comprobar el choque entre las teorías oficiales de las élites ilustradas y la práctica efectiva de los órganos del Poder se tomará como ejemplo indicativo, en el ámbito de este estudio, la obra de A. Arteta de Monteseguro ${ }^{12}$ a su vez fuertemente influida por el Discurso de Campomanes. El autor era miembro de la Sociedad de Amigos del País de Za-

9 Véase especialmente en Rodríguez CAMPOMAnes, P.: Discurso sobre la educación popular de los artesanos y su fomento, 1775, ed. F. Aguilar Piñal, Madrid, Editora Nacional, 1978.

10 Maravall, J.A.: «Del despotismo ilustrado a una ideología de clases medias: significación de Moratín» Coloquio internacional sobre Leandro Fernández de Moratín, Abano Terme, Piovan, 1980, pp. 185-186.

11 SánChez-Blanco, F.: «Dinastía y política cultural», Los Borbones. Dinastía y memoria de nación en la España del siglo XVIII, ed. P. Fernández Albaladejo, Madrid, Marcial Pons, 2001, pp. 570-571.

12 Arteta de Monteseguro, A.: Disertación sobre el aprecio y estimación que se debe hacer de las artes prácticas y de los que las exercen con honradez, inteligencia y aplicación, Zaragoza, Blas Miedes 1781 (pero escrito en 1778). 
ragoza y por lo tanto su tratado representa el punto de vista autorizado de los reformadores contemporáneos. Arteta empezaba su exposición lamentando

quán injustamente el vulgo grosero y ocioso, y la necia multitud de presumidos os disputaron la igualdad, debiendoos la preferencia.

Se dirigía a los trabajadores mecánicos para defenderlos de la opinión del vulgo, pero conociendo la administración de las leyes de caza habría que preguntarse si en la categoría de los presumidos también incluía a los gobernantes y a las clases superiores. Con las Luces, seguía Arteta dirigiéndose a los menestrales, "podéis ya, sin abandonar vuestros talleres, aspirar y llegar a la posesión de los honores y de los empleos distinguidos» pero el ejercicio de la caza era precisamente uno de los «honores» que se les rechazaba sistemáticamente. En el ideario social de la Ilustración la integración de los trabajadores mediante la concesión de prestigio social era un tema recurrente. Para Campomanes «Los artesanos, en esta parte, deben vivir subordinados a las leyes generales de la sociedad, de manera que no formen una especie de pueblo separado» y para ello había que reconocerles y restituirles la «Honra legal». Con el mismo fundamento la Sala de Alcaldes había comentado negativamente los estatutos de la Hermandad de Socorro de San José porque

conducen a excluir el motivo de que los oficios de las Personas pretendientes a la incorporación se comparen con otros oficios, y que resulte contra las Rs intenciones que los unos se tengan en menos que los otros, y para ebitarlo $[\ldots .$.$] bo-$ rrando las siguientes palabras, y oficios honrados y no mecánicos ${ }^{13}$.

Por otra parte la inversión de los valores tradicionales de nobleza/virtud o utilidad social era un elemento usual de cierto pensamiento moralista, y se puede encontrar en los ámbitos menos esperados, como en un tratadito de ética matrimonial:

La nobleza es una calidad puramente personal: la virtud es don intrínseco del alma, y no se propaga con la sangre: antes bien, enseña la experiencia, que la necia vanidad es el único don que acompaña, de ordinario, a los hijos de los Héroes $^{14}$,

en obras de literatura, en las que se ridiculiza el afán plebeyo de parecerse a la aristocracia, llamándolo "quijotismo» ${ }^{15}$, o como decía Cadalso "por cada uno

13 Campomanes, Discurso cit. p. 40; Hermandad de San José de Madrid, 31/X/1793, AHN Cons Leg 1687/13.

14 Consideraciones políticas sobre la conducta que debe observarse entre marido y muger. Madrid, Ramón Ruiz, 1792, p.13.

15 En esta dirección se mueven Jacinto María Delgado con sus Adiciones a la historia de Don 
que se emplee en un arte mecánica, habrá un sinnúmero que desean cerrar sus tiendas para ir a las Asturias o a sus montañas en busca de una ejecutoria» ${ }^{16}$; en los pensadores políticos como Cabarrús o Arroyal ${ }^{17}$, o en el texto de un escritor regalista como Joaquín Amorós ${ }^{18}$ glosando la Pragmática de 1776 sobre autoridad paterna para contraer matrimonio. La naturaleza del discurso reformista es inequívocamente ideológica, y su patetismo bienpensante y en definitiva vano se puede encontrar en la lírica de otro significativo ilustrado, Meléndez Valdés, en el Filósofo en el campo o en la Despedida del anciano ${ }^{19}$. La práctica de gobierno demuestra que por mucho que los gobernantes ilustrados afirmaran a veces lo contrario sus ideas sociales se apoyaban en buena medida en los prejuicios tradicionales de la organización social estamental y si este aspecto de la ideologia dieciochesca se ocultaba a veces con los discursos de exaltación de la productividad económica y de la mentalidad empresarial, se revelaba sin embargo, y crudamente, cuando se toman en consideración otros aspectos de organización de lo que los reformadores entendían por una sociedad bien regulada. Ejemplos se encuentran en todos los campos, como en el de la política de restricción de fundaciones de mayorazgos, donde el Consejo de Castilla lamentaba la emulación aristocrática

de todo género de personas, sean Artesanos, Labradores, Comerciantes, u otras gentes inferiores, presta un motivo freqüente para que ellos, sus hijos y parientes abandonen los oficios

en 1789. Claro está que las críticas de los gobernantes no iban dirigidas a la existencia del estamento noble sino a los afanes de ascensión social de los inferiores $^{20}$.

Quijote, de 1786, Pedro Gatell autor de la Moral de don Quijote de 1789 y la Moral de Sancho Panza, en 1791; Don Quijote Moderno, en Diario de Valencia de 29/XII/1798 como indica F. AgUILAR PIÑAL, «Anverso y reverso del quijotismo en el siglo XVIII español», Anales de literatura española, I, 1982, pp. 207-216. Las Adiciones... de Delgado serían una «burla sangrienta de los timbres y blasones nobiliarios» según DomingueZ ORTIZ, A.: Sociedad y Estado en el siglo XVIII español, Barcelona, 1976, nota 28 p. 357.

16 Cadalso, J.: Cartas Marruecas, Carta XXI. Alborg, J.A.: Historia de la literatura española, III, Madrid 1980, p. 747.

17 YUN, B.: «Sociedad patricia y gestión señorial, vistas desde la Ilustración», La gestión del poder. Corona y economías aristocráticas en Castilla (siglos XVI-XVIII) Madrid Akal 2002, pp. 177-305.

18 Amorós, J.: Discurso en que se manifiesta la necesidad y utilidad del consentimiento paterno para el matrimonio de los hijos de familia, Madrid, Blas Román 1777.

19 Caso González, J.M.: «La poesía comprometida de Meléndez Valdés», La literatura española de la Ilustración, Madrid, Un. Complutense, 1989, pp. 53-72. También reflejan las mismas inquietudes Gatell, P.: La moral de Don Quijote, Madrid, Josef Herrera, 1783; ID. La moral del más famoso escudero Sancho Panza, Madrid, Imprenta Real, 1793, y DeLGADO, J.M.: Adiciones a la Historia de Don Quixote, Madrid, Blas Román, 1786.

20 AHN Cons leg 5555/78. 
Los ejemplos son en la práctica incontables y reflejan que a partir de la segunda mitadad del siglo XVIII había en España una corriente de pensamiento que ponía seriamente en tela de juicio el valor tradicional de la aristocracia, y que muchos de los autores de esa corriente estaban muy cercanos al Poder o hacían incluso parte de los órganos de decisión política. Ahora bien, la Ilustración es un movimiento ligado a las capas sociales instruidas, y en ese sentido la Real Orden de 25 de marzo de 1773 marca una nueva, tímida mentalidad en la concesión de títulos, pues intenta premiar el mérito personal y no la sangre. «El principio del mérito personal es bastante significativo de los nuevos aires ilustrados», ha dicho Iglesias ${ }^{21}$, quien hace notar el prestigio social con que se reconocía al noble económicamente activo.

Pero sería ocioso seguir rastreando manifestaciones de este planteamiento social de sobra conocido. Sus contradicciones se deben a la naturaleza disociada de la intervención política reformadora que en el texto de Arteta aparecen con toda claridad, dado que el discurso no dejaba de ser en el fondo moralista, pues si reconocía y lamentaba las fatigas que debían soportar los trabajadores manuales para asegurar el ocio y el bienestar de los ricos, a renglón seguido aconsejaba a los artesanos que para hacerse más «dignos y recomendables» debían trabajar, adoptar «costumbres templadas y modales decentes», abatir su orgullo «con un porte honesto aseado y decente» y dedicarse a educar a sus hijos y aprendices. ¿Eran ésos los honores al alcance de los trabajadores manuales o sencillamente un mensaje para que hicieran suyos algunos de los valores sociales de las clases dominantes?22.

$\mathrm{Al}$ administrar la normativa sobre caza y pesca el Consejo demostraba que o bien no seguía las proclamas reformadoras o es que no había leído la formulación teórica de Arteta, cuando éste afirmaba:

todos nacemos iguales, todos deberíamos participar igualmente de las felicidades y de las desgracias. Si debe haber alguna distinción ventajosa, ¿No pertenecería más presto al que trabaja para alimentar a los otros? (p. 134).

Con la práctica de la caza se vuelve transparente la mentalidad aristocrática al considerarla propia y exclusiva de la nobleza y lo más significativo es que este punto de vista lo compartían en buena medida también los gobernados.

Por una parte, y bajo el punto de vista de los ministros ilustrados, estaba siempre presente la prevención contra cualquier tipo de diversión que pudiera alejar a los trabajadores de sus tareas productivas. Eso se comprueba en la política de reglamentación y reducción de las diversiones populares, pero los ejem-

21 IGLESIAS, C.: «La nobleza ilustrada del siglo XVIII español. El conde de Aranda», Nobleza y sociedad en la España moderna I, Oviedo, 1996, pp. 249-288.

${ }^{22}$ Los buenos consejos de los poderosos ocultan la economía depredadora de los más fuertes. YUN, op. cit. 
plos, en el caso de la caza, son también numerosos e igual de ilustrativos. El fondo de la mentalidad reformadora estaba dominado por el pavor a la ociosidad de los súbditos, y en ese sentido se entiende por qué en 1757 Manuel de Heredia y Torres, de la Junta de Obras y Bosques, escribía al Intendente de Palencia quejándose de la falta de respeto por la legislación de caza,

Que es tan general este vicio en la Provincia que ya puede estimarse en menos la aniquilación de la Caza, respecto de la olgazanería y daño que resulta a los Pueblos, pues el Zirujano, Barbero, Sastre, Zapatero, Herrero, y otros oficios dejando de travajar en ellos pierden la manutención de sus familias, hacen falta a lo necesario, y de olgazanes pasan a Ladrones, subiendo la insolencia a tal grado que hasta los Carniceros Mesoneros y otras gentes vajas usan de la diversión de la Caza, y la destrozan con livertad 23 .

He aquí un documento extremamente interesante porque fijaba los dos polos de la actuación sobre caza: se debían defender los venados de la aniquilación, pero este deber "puede estimarse en menos» si se comparaba con los perjuicios económicos que causaban - y sufrían- quienes cazaban. Se vuelve una vez más a la tarea de defender a la sociedad de ella misma y en último lugar aparecía, siempre presente, el miedo a la gente baja y a su insolencia. Admitiendo esto, se puede interpretar que el ejercicio de la caza se consideraba una barrera social para mantener a los súbditos en obediencia mediante la acusación de querer escapar del trabajo y mantenerse con la caza, acusación que será constante durante todo el siglo y servirá para justificar las exclusiones de ciertos grupos socio-profesionales del derecho a practicarla

pues los que huyen del trabajo, buscan el Pan por medios ilícitos, tomando por profesión, con capa de Cazadores, el ser destructores de ella.

En 1754 se repetía la idea, en Calahorra, al tomar ciertas medidas

también para que los oficiales, y personas humildes, y atareadas a las fatigas de su respectivo oficio para su sustento, no pudiesen salir a cazar $[\ldots]$ porque aficionados desmedidamente aquéllos a dicha Caza no sólo la extinguen sino que perjudican a sus mismas Casas y caudales, faltando al cuidado y manejo de ellos y a las tareas y oficios que se los han de aumentar, sustentar sus familias, permitirles únicamente a éstos el que los días feriados después de los divinos oficios puedan salir a cazar y divertirse con escopeta.

De esto comentaba el fiscal del Consejo: «Es mui conforme a la mente de S.M. para la Conserbación de la Caza. [...] No halla reparo». Al menos en este caso no se ocultaba que todo se dirigía a la conservación de los animales en

23 16/II/1757. AHN Cons leg 49549/2. 
beneficio de quienes sí podían cazar y no se mezclaban considerciones moralísticas con intereses venatorios como ocurría por norma general ${ }^{24}$. Las leyes citadas son de mediados del Setecientos y no se diferenciaban mucho de las del siglo precedente, marcando de esta manera una continuidad significativa y reconociéndola abiertamente, como en una Real Cédula de 1735. En 1685 se había legislado ya contra los malentretenidos que

sin tener hacienda propia, dexando el exercicio de sus oficios, y de acudir a las labranzas y cultivos de sus tierras, y heredades, se han dado a el vicio de Cazadores, con tal excesso, y soltura, que no viven de otra $\cos ^{25}$

y casi un siglo después las quejas eran las mismas: el Marqués de Camarena, que había construido a su costa «una Charca en el Baldío de la Zafra»

no pudo evitar con su celoso cuidado se originasen de una causa tan útil perjudiciales efectos, porque aficionándose desordenadamente los Oficiales artesanos a la Pesca, abandonan su principales ministerios, no atienden a la asistencia, y alimento de sus Casas, hacen sea vicio lo que deberían tomar por diversión, y lastimosamente se precipitan a una infeliz miseria ${ }^{26}$.

A partir de mediados del siglo Dieciocho las consideraciones sobre los perjuicios económicos ya no aparecen en las disposiciones legales probablemente porque hacia ese momento se va haciendo efectiva la reglamentación por la que oficiales y menestrales deberían cazar solamente en días festivos y nunca en laborables. Parecería que, cronológicamente, la primera mención legal a las limitaciones de los días útiles para caza en detrimento de los trabajadores mecánicos fuera la emanada en Álava en 1752 seguida poco después por la prohibición hecha a los «maniobreros» de Tembleque. En 1756 también Mallorca seguía las normas dictadas para cazar en El Pardo y limitaba al día festivo el único permitido a los «labradores Maestros y Oficiales de Oficios Onestos». Finalmente, en 1772 se establecía una normativa general de caza y pesca para todo el reino según la cual «Menestrales, Artesanos y Trabajadores y Oficiales mecánicos sólo podrán pescar en los días de Fiesta de Precepto, y usar de Caña». El uso de la caña además se limitaba a los días de fiesta y precepto también para Madrid por su Alcalde de Casa y Corte en $1787^{27}$. Luego no habrá que asom-

24 RO 28/II/1754 sobre veda de caza y pesca en bosques reales; las justicias debían cuidar para que los «desocupados» no se pusieran a cazar, AHN Cons lib 1481/10; Aprovación de diferentes Capitulos aumentados, a la Real Provisión de veda de Caza, y Pesca, 18/VII y 28/VIII/1754, AHN, Cons. leg 49546.

25 Mencionada en RC 21/XII/1735, AHN. Cons lib 1516/25.

26 30/X/1775, AHN Cons leg 4577/115.

27 Capítulos de Álava cit; Tembleque, 2/IX/1754, AHN Cons leg 49546; Ynstrucción general [...] Reyno de Mallorca cit; RC 16/I/1772 art. 14, AHN Cons leg 39465/4; Edicto de Joseph Antonio de Burgos, Alcalde de Casa y Corte, sobre veda de caza y pesca, 7/II/1787, art. 7, AHN Cons leg 39508/2. 
brarse si el Fiscal del Consejo reconocía que la restricción a los días festivos para los trabajadores mecánicos estaba bien fundada y que había que respetarla.

Por lo tanto deberá siempre tenerse en cuenta que una de las restricciones para practicar la caza se estipulaba en el sentido de no permitir a los trabajadores dependientes que descuidaran sus obligaciones. Es evidente que la idea central de esta norma se fundaba en convicciones economicistas y no tenía más connotación que la de proteger la racionalidad del trabajo productivo aunque se teñía muy fuertemente de consideraciones paternalistas; pero nada de todo eso ocurría cuando la formulación de las prohibiciones no se cubría de otras consideraciones que no fueran el reconocimiento explícito de la diferencias de clase y estamento. Declarar que las penas impuestas a los cazadores con arcabuces se debían aplicar

excepto si la tal persona fuere Noble, Eclesiástica, o que tenga mil ducados de caudal o hacienda propia en bienes raíces, o fuese de tal calidad, y circunstancias que no se pueda formar de ella sospecha de exceso, sino que le tiene para guardar su casa ${ }^{28}$

era muy distinto que recordar que los menestrales no podían ociar libremente. El caso del uso de arcabuces es especialmente significativo puesto que esas armas se podían usar para cazar pero también eran ofensivas y por lo tanto contra su posesión por parte de los grupos sociales más bajos se levantaban todos los prejuicios de los legisladores.

De hecho una de las máximas preocupaciones de los gobernantes, debido a su eficacia, era el uso de las armas de fuego; así, en Aranjuez, según las normas de 1721, «es sumamente perjudicial en dichos límites y sus cercanías, la manutención de los Arcabuzes en personas pobres, que sólo los mantienen para el exercicio de la Caza, y para herir, y matar, los Guardias de ella» y por lo tanto quedaban prohibidos a tres leguas vulgares del Real Sitio y de otros pueblos. Lo mismo valía para las escopetas ${ }^{29}$.

El mismo deseo de evitar que las escopetas estuvieran en manos de trabajadores se encuentra en la Real Cédula de 16 de enero de 1772, artículo 4, como se había establecido ya para Mallorca en 1756 y 1758 y muchas otras veces

28 RO 6/XII/1774 cit.

29 «Arcabuz, y escopeta, son armas de fuego conocidas y el día de oy las más practicadas en todo género de caça». Recordaba que se había prohibido ya su uso en 1610 en El Pardo y Valsaín en palabras de Cervantes, P.: Recopilación de las reales ordenanzas y cédulas de los bosques reales del Pardo, Aranjuez, Escorial, Balsaín y otros, Madrid, Melchor Álvarez, 1687, p. 36. Al igual que Ariosto, los tratadistas de caza lamentaban la introducción de las armas de fuego, que se habían cobrado una víctima ilustre: la ballesta, «Instrumento ya poco conocido de presente, por aver únicamente prevalecido el arcabuz» (Ibid. p. 38). Moratín también tenía baja opinión de las armas de fuego: la caza había sido deporte noble «hasta que halló el Averno / la invención de la pólvora tremenda». N. Fernández Moratín, La Diana o arte de la caza. Poema dedicado al serenísimo Señor D. Luis Antonio Jayme de Borbón, Madrid, Miguel Escribano, 1765, I ${ }^{38}$. 
antes $^{30}$. La misma prevención contra armas de fuego en manos de «los artesanos, menestrales, y empleados en oficios semejantes» se hacía notar en la petición de los procuradores y síndicos de Segovia en 1788. Siempre para salvaguardar la caza, se pedía entonces que se limitara, si no «a toda clase de personas» al menos a las categoría sociales privilegiadas ${ }^{31}$. Una vez más se equiparaban furtivos y delincuentes comunes:

Que en algunos rovos y asaltos de casas acaecidos en estas Poblaciones se ha notado, que los delinquentes llevaban Armas de Fuego viejas, y mal aparatadas, dando noticia de las casas, dueños y efectos que tenían, de lo que se sospecha que algunos fueron de esos menestrales Paisanos Pobres y mal entretenidos que a bueltas de hir a cazar, coayubaron a dichos ynsultos.

La prohibición era algo más que una simple prevención de posibles delitos; se trataba sobre todo de repetir y defender un ideal aristocrático centrado en la práctica de la caza que no sólo era y debía seguir siendo un pasatiempo de las clases superiores, y además incluso los modos de practicarla se debían adaptar a la calidad de las personas a quienes les estaba permitida.

Los tratados contemporáneos abundan en afirmaciones sobre lo que eran instrumentos más nobles para cazar, como decía Arellano, y de manera programática desde el Prólogo al lector de su obra se patentizaba el espíritu aristocrático de esa ocupación:

Mi instituto sólo es, el tratar del modo liberal, que es el de la escopeta, por ser más limpio, racional y propio de personas Reales, y de otras constituidas en Dignidad.

Con presupuesto semejantes no debe ser extraño que se prohibiera a los menestrales el uso de escopetas ${ }^{32}$.

También, como signo profundamente clasista, estaban severamente prohibidos los perros de caza por Aranjuez 1721, en buena lógica en las mismas zonas de prohibición de los arcabuces; en 1781 para El Pardo, a propósito de perros, se especificaba que los dueños o arrendadores de tierras de labranza en los límites del cazadero real podían tener

dos perros podencos registrados y los Guzcos permitidos, con tres hombres en mano limitadamente para ahuyentar la caza mayor y menor pero no matarla.

La demarcación clasista ahora se hace evidente, porque quienes sí podían tener perros eran los propietarios de tierras, pero sólo para espantar los venados

30 Ynstrucción general [...] Reyno de Mallorca cit; Ordenanzas de las Alcaldías del Pardo cit; RO 28/II/1754, AHN Cons leg 49495.

31 Petición 4/IX/1788 y resolución del Fiscal 27/VI/1789, AHN Cons leg 39510.

32 Arellano, op. cit. p. 3. Lo mismo en Calvo Pinto Velarde, A.: Silva venatoria, Madrid, 1754. 
que hubieran entrado en sus tierras, no para cazar. Naturalmente los perros prohibidos se confiscarían y matarían, al igual que se deberían destruir los otros instrumentos. Esta era la legislación que se aplicó a todo el reino.

A primera vista la severidad de las disposiciones legales parecería solidísima, mas la mayor parte de estas prohibiciones daban lugar a su vez a la posibilidad de rodearlas legalmente mediante una licencia específica, cuya concesión es una vez más un claro exponente de la mentalidad aristocrática, según se verá más adelante. Primero conviene considerar el sistema de castigos previsto para los infractores, en el que se sancionaba la diferencia ante la ley de plebeyos y nobles. Bujanda lo admitía llanamente, justificando que las penas debían graduarse según la cualidad del reo, para noble o caballero,

por ser más conforme a su estado este divertimiento, que con el rústico Labrador, u Oficial, que está dado, y dedicado a la labranza, y oficio, para buscar comida 33 .

Significaba una vez más reiterar la conciencia clasista y aristocrática del legislador.

Pero, a pesar del rigor de estas medidas, en 1773 en Lérida, en 1774 en Reus, en 1778 en Alforja (Tarragona), en 1779 en Granyella (Lérida), en 1783 en Mataró, en 1790 en Arnes (Tortosa) y en 1789 en Barcelona se concedieron todas las peticiones de licencia de caza con armas de fuego. En todos los casos los solicitantes declaraban ser «hombre de buena fama, y costumbres, y afecto al Real Servicio», aunque el fiscal no olvidaba hacer constar, como en Graneyella, que

En el Principado de Cataluña está prohibido el tener y usar armas de fuego, y la real Audiencia y su presidente proceden con gran cuidado en conceder licencias para llebarlas [...]. Los pueblos tienen a prevención escopetas de Conzejo, que entregan las Justicias a ciertas personas en caso de algún alboroto, somatén u otro Lance, en que sea conveniente el sosiego público. Es cierto que el Corregidor informa de las buenas circunstancias de Francisco Castelló y que es acreedor a que se le conceda el uso de escopeta, como solicita. Pero también lo es que por este medio se irá llenando el Principado de armas y quedará iludida la general prohivizión de su uso. Por esta razón deve escusarse quanto sea posible el conceder semejantes licencias; y quando el Consejo tenga a bien dispensar esta gracia a Castelló convendrá sea con las limitaziones y calidades que explicó en su respuesta de 13 de marzo de 1779 respectiba a la solicitud de Pedro Mestre [vecino de Alforja].

Fuera con o sin limitaciones, era un hecho que las licencias se concedían, por mucho que el fiscal del Consejo dejara entrever razones contrarias y amenazas posibles al orden público, políticas y de respeto por las jerarquías sociales. Por otra parte, las peticiones se tramitaban en bloque, como si se hubiera tra-

33 BUJANDA, op. cit. pp. 15 ss. 
tado del trabajo de un lobby de presión o de un grupo social de especial importancia, aunque nunca se llegará a saberlo con certeza. Y tampoco se llegará a conocer - pues no justificó su decisión - las razones que tuvo el mismo organismo para rechazar las peticiones de licencia a otros habitantes de Cataluña por los mismos años ${ }^{34}$.

Es decir que se presenta inmediatamente el asunto de la concesión de licencias de caza, con lo que se puede hacer luz sobre una característica del despotismo ilustrado que consiste en que el sistema permitía —incluso fomentabael recurso a la petición de gracias especiales para salvar las medidas de prohibición y veda que el Poder mismo había impuesto de manera aparentemente tajante. Era un hecho que se daba prácticamente en todos los ámbitos de las reglamentaciones legales, desde las imprentas a las regalías de aposento, y que por supuesto abundaba en el caso de la caza. La normativa vigente en el Setecientos imponía la prohibición de cazar con armas de fuego, de usar galgos y hurones, o sencillamente, para ciertas capas sociales, la prohibición pura y simple de practicar esa actividad. Y por lo mismo, inmediatamente, la Junta de Obras y Bosques recibía las peticiones de licencia para no respetar lo que se había legislado, naturalmente tras el pago del servicio necesario. En 1807 la gracia ordinaria para poder cazar costaba trescientos reales, aunque no se menciona explícitamente ninguna tarifa en los expedientes del Dieciocho ${ }^{35}$. Las peticiones eran muy numerosas, y podrán ser útiles para trazar un esbozo de la mentalidad social subyacente en el asunto de caza, y también de la práctica de gobierno seguida por los ministros ilustrados.

Se habían prohibido tajantemente los hurones desde 1721, pero entre 1760 y $1763^{36}$ se solicitaban licencias para usarlos, y el Consejo las concedía a mansalva a quienes aducían por justificación de sus pretensiones el hecho de ser propietarios o arrendadores de cotos de caza de conejos. Luego se trataba de una medida claramente en pro de los labradores ricos, y que discriminaba a los jornaleros y menestrales. Gregorio Carmona, de Añover de Tajo, arrendador principal de la casa del Soto propio de ella alegaba

como consta de las condiciones de su arrendamiento que para aprobecharse de dicha Caza necesita el cazarla con los armadijos de caza que por costumbre son necesarios, y siéndolo uno de ellos el de los urones.

Estando a esos principios todo el mundo debería Poder haber usado hurones, puesto que todo el mundo como es lógico quería aprovecharse de la caza;

34 Las licencias se concedieron el 5 de mayo de 1790, para los tiempos permitidos por la veda y se rechazaron a José Jordá y Torrens, de Segur, a Francisco Llordella, de Torba (Cervera), o a Francisco Milá, de Mombuy (Villafranca Penedés), "por ahora», AHN Cons leg 39490/8.

35 Como puede verse por el expediente de Pedro del Rincón, de Toledo, el 16/IX/1807, AHN Cons leg 39523/1.

36 AHN Cons leg 49504. 
el factor discriminante de este caso consiste en el hecho de que Carmona había arrendado el Soto precisamente para poder cazar. Se trataba una vez más de un pudiente que había invertido un capital, no de un pobre ${ }^{37}$.

Bastante más interesante será el caso de una petición presentada en 1776 por D. Joseph Iturrigaray, capitán del regimiento de Alcántara, «para sacar de la Caja general los urones necesarios a la Caza de conejos en los sembrados de la villa de Ocaña, por los daños que hacen, y no poderse extinguir de otro modo, estando prohivida la Escopeta por la inmediación al Real Sitio de Aranjuez». Es que decía que estaba actuando «a instancias hechas por los Labradores de esta Villa», pero el fiscal rebatía

que esta parte no es Labrador, ni da a entender que sea hacendado en dicha Villa de Ocaña, ni otro interés propio que el de divertirse en la Caza con Urones, ya que no puede con Escopeta [...]. Aun el auientar solo la Caza de los Sembrados, por otros medios, está solo permitido a los Labradores como interesados en la conserbación de sus frutos por la RC de 27 de Abril de 1771. Los Urones se hallan absolutamente prohividos en 8 leguas encontorno del Real Palacio de dicho Sitio excepto a los dueños de Sotos inclusos en él.

Conviene notar que el fiscal ponía el acento en que la parte no era un labrador — es decir, no tenía hacienda - y además que si deseaba usar de esos animales era porque no podía cazar con escopeta: en el fondo deseaba cazar por el gusto de practicar ese deporte. Con semejantes razones se podría esperar que la petición fuera rechazada, pero en cambio la Junta de Obras y Bosques la aceptaba porque decía que tal vez tuviera alguna utilidad ${ }^{38}$. El poder absoluto no necesita justificar sus decisiones.

Los galgos se consideraban instrumentos de caza propios de las clases sociales más altas, y por lo mismo se prohibían directamente a los plebeyos, pero sin embargo se podía pedir licencia de tenerlos y usarlos, presentando la solicitud al acalde para que la tramitara al Juez de Montes del Consejo de Castilla. En 1769 el licenciado don Vicente Brasino presbítero beneficiado párroco de San Pedro de Amusco pedía permiso de tener galgos para «recreación y alivio de su salud» y antes de emitir su parecer el Consejo lo primero que quería saber era «si es Noble, y si seguirá algún perjuicio en que se le conceda la licencia» ${ }^{39}$. Aquí se presenta en toda su crudeza la mentalidad social dominante pues parece que el único aspecto que interesaba al legislador cuando recibía las peticio-

37 27/VIII/1770. Concedido «con arreglo a la RC 3/III/1769», AHN Cons leg 49495. Para el mismo año de 1770, varios casos más en AHN Cons leg 49496.

38 Era una decisión que chocaba frontalmente con las leyes vigentes, como reconocía el mismo fiscal, por ejemplo con cuanto establecido por la Real Cédula 22/XII/1748 art. 16, AHN Cons leg $39499 / 14$.

39 4/IX/1770, AHN Cons leg 49495. Para el año de 1769 la contestación usual del Consejo era la misma. AHN Cons leg 49501. 
nes era saber si el solicitante pertenecía a la nobleza o no. Se trataba sin duda de una mentalidad aristocrática que existía en el momento de emanar las leyes y los reglamentos pero que se vuelve aún más evidente en el momento de aplicarlos. Así se concedía el uso de galgos a los hermanos Clemente y Juan Antonio Ceynos de Cuenca de Campos porque, como ellos mismos habían afirmado,

poseen diferentes Haciendas suyas propias y que son Labradores, y de la primera distinción del Pueblo, de buena vida y de más apreciables circunstancias,

o a Juan de Paredes Fuentes, Fernando de Paredes Redondo y Francisco Nogales Núñez, de Frechilla en Palencia, en cuya petición

se acredita ser tales Labradores Hacendados en dicha villa con dos pares [de mulas] de Labranza, y Personas que han regentado, y regentan los empleos de República y por lo mismo capazes para mantener un par de Galgos,

es decir estando a meros criterios económicos y de preferencia social. Don Gregorio Dana de Vallecas conseguía obtener la licencia deseada sin más mérito que el de haber

dexado absolutamente los Estudios, y tenido por del estado secular, y de las mejores combenienzias para la manutención de su persona ${ }^{40}$,

y por los mismos criterios de valoraciones socio-económicas se rechazaba a otras personas: se reconocía abiertamente que las condiciones para conseguir licencias de caza eran puramente de posibilidades económicas. Francisco Lucas Moral, «administrador de la Casa y Hacienda que el Rey tiene en la villa de Arganda», dado que las disposiciones legales decían que no se podía tener galgos sin ser dueños de «dos pares de mulas», hacía notar que «no sólo tiene los dos pares, sino Nueve a su Cargo y Dirección» por lo que se sentía justificado para aspirar a la licencia de tener dos galgos. El magistrado pedía un informe al gobernador de Aranjuez y éste contestaba:

No conociéndosele vienes algunos raíces a Francisco Lucas Moral vecino de la Villa de Cienpozuelos, residente en la de Arganda administrando la Casa ocupada por la temporalidad a los Regulares que fueron de la Compañía, no le considera con las proporciones que requieren las órdenes generales, y particulares para el uso de Galgos ${ }^{41}$.

Luego era necesario poseer bienes o capitales o gozar, en suma, de una posición destacada en el lugar. Se permitía cazar a Francisco Martín de Francisco

40 AHN Cons leg 49494.

41 AHN Cons leg 49493. 
familiar del Santo Oficio, con hacienda propia de «Casas, Majuelo, Tierras y olivas y ganados lanares» en Toledo, o a Joseph Antonio Morales, regidor por el estado noble de Estremera, y a su hermano, «sugetos de los más hacendados de esta enunciada Villa, en la que son tenidos y reputados por Hijosdalgo y de consiguiente de las familias más distinguidas de ella»" $»^{42}$ "Personas de distinción» en sus respectivos pueblos eran aquéllas a las que se debía permitir el uso de perros desde la Real Provisión de 7 de marzo de 175443 para disfrutar de «la justa, y honesta libertad de cazar»; en 1756, en Mallorca, la caza debía quedar permitida para los «hombres honrados», y por tales se entendían los propietarios de predios de "primera, segunda y tercera clase», que podían sin embargo disponer de un número distinto de perros; y siguiendo las mismas Instrucciones, la casuísitica social limitaba perfectamente varias categorías:

Cavallero aficionado, hombre hacendado, persona distinguida por su calidad y empleo, profesión y estado [...] labradores Maestros y Oficiales de Oficios Onestos, y demás gente bien opinada en quienes no recaiga sospecha de exceso [...] prohiviendo enteramente este uso y exercicio a las demás personas, y oficiales de egercicio vajo, que sean sospechosas

siguiendo una graduación descendente establecida principalmente por la propiedad pero que en ningún caso era privativa de las Baleares. La importante medida de 1772, válida para todo el reino, decía que los galgos se debían reservar a

los que huvieren justificado las calidades de hacendado, o persona de distinción, conforme a mi Real Orden de 10 de Julio de sesenta y dos, y que tengan licencia de mi Consejo en Sala de Justicia.

Lo que no era una novedad porque el favor concedido a los hacendados o personas honradas ya se había sancionado por las leyes de El pardo en 1752, que son la verdadera espina dorsal del edificio normativo sobre caza y pesca, y éstas a su vez remitían a una medida de la Junta de Obras y Bosques de 1735 en la que se estipulaban las categorías de propietarios o arrendatarios según sus haciendas fueran superiores o inferiores a los seiscientos ducados ${ }^{44}$.

Manuel Guerrero, vecino de Santa María la Real de Nieva, no podía cazar porque era sastre, y Francisco Antonio Salas, de Madrid, por ser criado - mayordomo- del conde de Puñonrrostro ${ }^{45}$. Sería posible hacer una lista de los oficios

42 AHN Cons leg 49495, fecha de 1770.

43 AHN Cons lib 1517 f. 65.

44 RC 14/IX/1752, AHN Cons. lib 1480/65 y RC 21/XII/1735, AHN Cons lib 1516/25. Ordenanzas de las Alcaldías del Pardo 4/VII/1781 cit; Edicto del Alcalde de Casa y Corte 7/II/1787 cit. En 1721 en Aranjuez se permitía cazar al vecino «que tenga dos mil ducados de caudal, y hazienda propia, y bienes raízes, y con la calidad, de que no excedan de dos Arcabuzes en cada Casa», 21/I/1721. AHN Cons leg 39467/9.

45 AHN Cons leg 49493. 
que se consideraban indignos de aprecio, sacándola del conjunto de peticiones de licencia de caza: cirujano, boticario, maestro de obra de prima, cerero, capitán de milicias, panadero, o para concluir, carnicero, y para este último caso se explicaba el porqué:

Siendo carniceros de Oficio no corresponde permitirles el uso de Galgos, ni el de cazar en ningún tiempo, aun sin ellos, y menos con el aparato de Caballo y Perros, equibocándose con las personas más distinguidas, quando ni aun deven considerarse en la clase de jornaleros para permitirles la diversión de la Caza con Escopeta los días festivos, mediante que los Carniceros en qualquiera días están, y deven estar ocupados en su oficio ${ }^{46}$.

El fiscal del Consejo formulaba una visión aristocrática de la sociedad que no dejaba resquicio a la duda. Excepto la última, todas estas peticiones se fechaban entre 1769 y 1770 y eran la primera reacción de los cazadores a la Ordenanza de 1769, lo que explicaría también las declaraciones explícitas de la Junta de Obras y Bosques, porque el gobierno quería dejar, desde el primer momento, claramente sentadas las reglas del juego. Naturalmente no todas las peticiones se rechazaban, incluso para el mismo año de 1770 los expedientes de los legajos 49495 y 49506 del Archivo Histórico Nacional ofrecen una serie de peticiones todas aceptadas, presentadas esto sí, en su totalidad, por sujetos acomodados. A partir de esa fecha parece que la concesión de una licencia de caza se hiciera cada vez más difícil, y empiezan a aparecer los casos de aspirantes que a raíz de los criterios anteriores deberían haber recibido una contestación favorable y que en cambio se veían rechazar sus pretensiones. En 1774 el propietario de una casa valorada en 10.000 ducados y de dieciséis mulas de paso «cuios útiles le rinden sobradamente sin necesidad de asistencia personal» porque efectivamente tenía «los correspondientes Criados para su manejo» no obtenía la licencia solicitada porque según el Consejo su riqueza procedía del negocio de las mulas de alquiler. De nada valía que tuviera también dos criados para su servicio personal, o al menos esa situación no conseguía borrar la sospecha de realizar o de haber realizado trabajo manual ${ }^{47}$. Además parece como si más tarde, en los años ochenta del siglo, se empezara a descontar la excesiva generosidad de los años anteriores, lamentando que hubiera demasiados aficionados a la caza que amenazaban la diversión del rey. Por eso se les rechazó la petición a don Alejandro de Heredia presbítero y a don Joseph González clérigo de menores de Illescas:

pues además de no tener por sí otros bienes, ni rentas, que las que producen sus cortos Beneficios, se conoce por el citado antecedente el abuso que hai en dicha Villa de dedicarse a Cazadores muchas personas a quienes no compete esta

46 AHN Cons legajos 49493, 49501, 49499/22.

47 Juan de Castro, Valladolid, de 50 años, viudo, 22/VIII/1774. AHN Cons leg 49506. 
diversión con el riesgo de excederse por estar tan cercanos los Bosques Reales de Aranjuez ${ }^{48}$.

Sea como fuere, el balance general del estudio de los expedientes de licencia de caza indica que en su gran mayoría se admitían todas las peticiones, lo que automáticamente plantea la pregunta de para qué se emanaban las normas de prohibición ${ }^{49}$ y esto es especialmente interesante a la vista de la «famosa» Real Cédula - como coinciden en calificarla Domínguez Ortiz y C. Iglesias- de 1783. Con esa medida se anulaba el baldón de vileza que debían soportar los oficios manuales pero los resultados desde luego no fueron todo lo deseado. Como ha dicho Domínguez Ortiz, se trató de una concesión formal que no hacía mella ni en la mentalidad social del país ni en las convicciones de sus magistrados ${ }^{50}$.

Al llegar a este punto se ha visto que las licencias se pedían apoyándose en la situación de privilegio socioeconómico del solicitante; sin embargo conviene hacer algo de luz sobre otro aspecto de la caza, que indica una sensibilidad social y cultural distinta, y al que a menudo se recurría: las consideraciones terapéuticas de la actividad venatoria. El hecho de que tal vez se tratara de un ardid para conseguir la licencia no invalida el interés del planteamiento, porque si la Junta de Obras y Bosques admitía el fundamento de esas razones quiere decir que se abría camino en el sentir de los grupos dirigentes la asociación entre salud y práctica del ejercicio físico. Cuando los aficionados a la caza deseaban conseguir su licencia, algunos de ellos se presentaban afligidos por enfermedades o malestares que se remediarían gracias al ejercicio. Para obtener la licencia de caza entonces era justificación suficiente sentirse desde

tres años ha insultado de varios vaídos de cabeza originados de una vida sedentaria y sumamente quieta i melancólica ${ }^{51}$,

exponer como hacía Juan Rodríguez, presbítero de Aveinte (Ávila), ser de

Pingüe renta, reducido en vecindario, sin anexos, y allarse con quebrantada salud, y para el recobro de ella, necesita de algún exercicio, y siendo el más propio para conseguir dicho veneficio, el de la $\mathrm{Caza}^{52}$,

48 9/I/1784, AHN Cons leg 39502/7. O podía ocurrir que se descuidaran las actividades necesarias a la sociedad para dedicarse a divertirse: en 1785 se concedieron todas las licencias pedidas menos la de Manuel Nieto Martín porque, al ser el escribano público de Illescas debía estar siempre localizado y a disposición del publico.

49 Por ejemplo de 1782 a 1797. AHN Cons legajos 39502, 39505, 39511 39508, 39500, 39523.

50 Dominguez OrtiZ, A.: Sociedad y Estado en el siglo XVIII español, Barcelona, Ariel, 1976, p. 353; IGLESIAS, C.: «La nobleza ilustrada del siglo XVIII español. El conde de Aranda», Nobleza y sociedad en la España moderna I, Oviedo, Nobel, 1996, pp. 249-288.

51 Dr. Diego Antonio Parreño, colegial del Mayor de San Ildefonso de Alcalá de Henares, 27/VI/1755. AHN Cons leg 49506.

52 13/IX/1770, AHN Cons leg 49495. 
o como el caso del boticario de Alberite, certificado por la autoridad del informe del «médico y zirujano» local:

siendo así ser de edad de treinta y dos años de edad poco más o menos se halla muy frequentemente enfermo de diferentes simpthomas, sin que aiamos podido allar hasta aora otra causa, que la de ser de una naturaleza crasa, lo que se deja conocer de que en no empleándose por algún tiempo más que en las maniobras de su facultad, luego enferma, siendo su remedio, y en el que más a allado alibio el acer exercicio andando con exceso en el campo, aunque sea con sol asta que canse algún tanto la naturaleza.

Las dos peticiones se recibían favorablemente; pero cuando el boticario pedía permiso para confiar su botica a otro colega mientras él iba a caza, se le negaba la posibilidad porque su deber consistía en prestar servicio a la comunidad ${ }^{53}$.

Del analisis del conjunto de la práctica administrativa y de gobierno se puede ver cómo bajo el sistema legal de la reglamentación de la caza se manifiesta una mentalidad aristocrática muy activa durante el siglo Dieciocho. Era evidente la preocupación por el orden público y, tal vez, una premonición de la grande peur que se estaba preparando en Europa, pero no es sucificiente este aspecto para explicar toda la construcción legal. Preexistente, en la mentalidad del legislador, debía estar, hondamente enraizada, la conciencia de clase, de pertenencia a un grupo social privilegiado y superior, único al que se debía permitir la práctica venatoria y entonces la prohibición de caza aplicada a las capas sociales subalternas adquiría un valor simbólico de separación tangible entre clases sociales; antes de sostener que los trabajadores podían delinquir si se les permitía tener escopetas, era necesario estar convencidos de que la caza era asunto para los privilegiados ${ }^{54}$. Y los legisladores lo creían y no se recataban

53 Francisco Javier Ybarra boticario de Alberite, Logroño, 24/VII/1770, AHN Cons leg 49493. En cambio no se concedía nada a Tadeo de Lucas de Zaragoza, «colegial de el de Zereros, y Zucureros de ella con Casa y Botiga», «mediante padecer algunos achaques, para la conserbación de su Salud se ha exercitado en la lícita diversión de la Cazería algunos ratos que le permitían sus ocupaciones» ni a Joseph Lasaga de Zaragoza, ni a Manuel de los Santos, criado guardarropa del marqués de Baldecarzana de Madrid, que «Se halla vastante melancólico, de resultas de una enfermedad». AHN Cons leg 49506.

54 El sentido aristocrático de este deporte lo indican MORÁN-CHECA, Las casas del rey, Madrid, El Viso, 1986, p. 26: «Y es especialmente por esto, para acentuar el carácter restrictivo que tiene, por lo que la caza se protege y se restringe su práctica a las clases sociales menos favorecidas» (p. 27). Hablan del Cinco-Seiscientos pero se ha visto que en el Siglo de las Luces la música era la misma. En el siglo XX Mariategui y Pérez BARradas, A.: Historia de la montería en España, Madrid, s.n, 1934, mantenía muchas actitudes de justificación del clasismo venatorio. «En uso de su perfecto derecho, [los grandes señores] han obligado a respetar las leyes vigentes respecto a vedas y cotos, con lo cual al mismo tiempo cumplían uno de sus deberes, pues los efectos de aquella legislación, sabiamente aplicada, son provechosos en alto grado a las clases humildes. Es verdad que gozaban del placer de la Caza los propietarios, pero no es menos cierto que el beneficio de ella iba a parar a los menesterosos, proporcionando trabajo de guardas o de ojeadores en regiones donde el 
en afimarlo y en este sentido tal vez fuera interesante trazar un paralelismo entre la expresión cruda de la mentalidad clasista de los gobernantes españoles y el sistema de dominación social en la Inglaterra coetánea, donde la Ley en cambio aparentemente era imparcial en sus aspectos formales ${ }^{55}$.

«Honra en perros, y escopeta» ${ }^{56}$. Es un verso de una sátira entre tantas muchas del estado de cosas en España, criticando la política y la sociedad del Setecientos; puede querer decir que se daba honor a quien podía mantener unos perros de caza, como también que el honor social se apoyaba en criterios superficiales de apariencia u ostentación. En ambos casos, es el diagnóstico de una sociedad estamental aún demasiado cerrada, aún antigua y anticuada, lejos todavía de la organización burguesa moderna que se estaba mientras tanto abriendo camino en otros lugares de Europa.

rendimiento de los cultivos es escasísimo y haciendo conocer bellezas naturales antes ignoradas. No olvidemos que la mayor parte de la carne de las reses cobradas se destinaba siempre a los Hospitales o Casas de Beneficencia más cercanos a los Cotos» (p. 381).

55 Benton, L.: Law and Colonial Cultures: Legal Regimes in World History, 1400-1900. Studies in Comparative World History, New York - Cambridge, Cambridge Un. Press, 2002.

56 Apuntaciones de un cronista... 1775. BNM mss 10955, f. 133v. 